\title{
A New Pedagogy for Training the Pre-service Mathematics Teachers Readiness in Teaching Integrated STEM Education
}

\author{
Usman Galadima, Zaleha Ismail, Norulhuda Ismail
}

\begin{abstract}
The development of any country in the world depends largely on its escalating focus on integrated science, technology, engineering, and mathematics (iSTEM). Over the years in Nigeria, there are calls for action to integrate STEM disciplines as the pre-service teachers are only receiving training in the separate field of STEM. Therefore, the purpose of this study was to determine the effectiveness of the iSTEM course as a new pedagogy for training the pre-service mathematics teachers' readiness in teaching the iSTEM disciplines in Sokoto State, Nigeria. The study utilised one group quasi-experimental research design. Purposive sampling was used in choosing all the 54 pre-service mathematics teachers in their 300-level undergoing a teacher training programme in Sokoto State University, Nigeria. The participants underwent a 5-week iSTEM course organised by the researchers that focused on the five levels of integration that include: Single, Combine, Multiple, Engineering Projects, and Fully Integrated STEM disciplines. Data was collected through the iSTEM pre- and post-survey Questionnaire (iSTEM-SQ) and analysed using descriptive statistics. The bar graph and non-parametric Wilcoxon Signed Ranks test were also used in describing the effectiveness of the pre- and post-survey test. The findings indicated that the iSTEM course was effective in preparing and empowering the pre-service mathematics teachers' pedagogical strategy for teaching integrated STEM in their future classroom instruction. The paper also recommends for incorporation of the iSTEM approach in the curriculum of pre-service mathematics teachers at the various institutions of learning in Nigeria.
\end{abstract}

Keywords: Integrated STEM, iSTEM Course, Pedagogy, Pre-service Mathematics Teachers.

\section{INTRODUCTION}

The integrated Science, Technology, Engineering, and Mathematics (iSTEM) is a new pedagogical strategy that emphasizes application linking holistically all the Science, technology, Engineering, and mathematics (STEM) disciplines. The new pedagogy for training pre-service mathematics teachers is aimed at preparing them for a proficient iSTEM approach to enable the learners to actively observe and explore the learning environment of iSTEM-based approach that help to tackle the 21 st century challenges and national economic growth and development $[1,2]$. Ideally, the trend in the whole world is moving towards

Revised Version Manuscript Received on April 19, 2019.

Usman Galadima, Department of Science Education, Sokoto State University, Sokoto, Nigeria. Email: usman.galadima@ssu.edu.ng

Zaleha Ismail, Department of Science, Mathematics and Creative Multimedia Education, Universiti Teknologi Malaysia.

Norulhuda Ismail, Department of Science, Mathematics and Creative Multimedia Education, Universiti Teknologi Malaysia.

iSTEM education and programmes (Evans, 2015). In line to this, the developed nations viewed iSTEM education as cohesive and they focused on the interconnectivity of all the STEM disciplines [3, 4]

Building on the above, over the years in Nigeria, there are calls from stakeholders in education for action to integrate STEM disciplines as the pre-service teachers are only receiving training in the single and separate field of STEM [5, 6]. The consequences associated with this kind of iSTEM instruction is that it is likely to single discipline pedagogy may not help the learners to understand the connection between and within STEM disciplines. Thus, an effort to shift to the iSTEM learning domains approach from teaching in the single STEM discipline, the researchers trained and prepared the pre-service mathematics teachers with a new pedagogy that developed their skills to facilitate in an iSTEM approach in Sokoto State, Nigeria. The iSTEM approach if not implemented in Sokoto State, it will affect the productivity of the learners. Thus, for the pre-service mathematics teachers to move from the existing approach of teaching separate STEM subjects and to shift in promoting the iSTEM education in Sokoto State Nigeria, there must be a strong focus on teacher's preparation course on the iSTEM education $[5,7$, 8]. For the above reasons, this study designed the iSTEM course training to prepare the participants with an iSTEM pedagogy that will develop their skills to facilitate the teaching of the iSTEM course. This paper discusses the 5-levels of pedagogical strategy for teaching iSTEM course, and the effectiveness of the iSTEM course in the training of pre-service mathematics teachers in Sokoto State, Nigeria.

\section{BACKGROUND OF THE STUDY}

Many studies have been conducted in the last decade investigating and examining pre-service teachers with regards to the iSTEM into their instruction [9-14] These studies all focused on providing meaningful learning requirements for pre-service teachers, encourage in integration and collaboration within the classroom's instruction. This is in conformity with Stohlmann, Moore [3] statement on consideration for teaching the iSTEM education that the teaching of integrated science and mathematics provide a good basis for teaching iSTEM course. 
For the above reason, the rationale for increasing preparation and careers in STEM fields is to develop the STEM-capable workforce that improves the iSTEM literacy of all students for future needs for more engineers, technicians, scientists, and mathematicians (such as: Petroleum Engineers, Chemical Engineers, Software developers, Information security analyst, Industrial psychologist, Architect, Actuarial Scientist, Medical Scientist, Cost estimators, Statistician, Web Developers, etc) and the necessity for more innovative and creative workforce [15]. Together, this rationale supports the continually growing demand for the required STEM skills to meet the present and future global economic and social challenges [16, 17]. Similarly, Zollman [18] outlined the purpose of integrated STEM education for resolving (i) community needs for new scientific and technological advances; (ii) economic needs for providing national security; (iii) personal needs to become a fulfilled, knowledgeable and productive citizen. Due to this purpose that Bybee [19] view integrated STEM education reforms under three key goals: (i) a response to global economic challenges; (ii) recognition of the requirement for STEM literacy for solving global environmental and technological problems; and (iii) a focus on the realisation needed to foster the 21 st century workforce skills.

Aligning education reforms with the iSTEM education, it is pertinent to note that the growing attention and importance have been given to mathematics as one of the components of STEM education due to the fact that without mathematics there is no science, without science there is no modern technology and without modern technology there is no modern society $[20,21]$. In supporting this assertion, mathematics is the alpha and omega, as well as the queen of science and technology and the only necessary element in modern social development. This suggests that there could not be real technological development without a corresponding development in mathematics both in understanding and in practice $[6,7]$.

Furthermore, it has been correctly discovered in Bajah [22], no nation can make significant progress in this era of information technology, particularly in educational development without which science and mathematics are based. In this regard, despite the importance of mathematics education, Salau [23] mentioned that the form of its better understanding remained difficult. To this end, many problems seem to influence the teaching and learning of mathematical education in Nigeria. These problems led to the low performance in secondary education on the subject [23]. Some of these problems include severe shortages and qualified teachers of professional mathematics; shows a lack of knowledge of the content of mathematics by many mathematics teachers; crowded mathematics classrooms; and traditional teaching methods despite exposure to more viable alternatives. In essence for science and technology take their root defined in our society, the poor state of mathematics education must be rectified. This could be achieved by clarifying the issue in the Nigerian class and integrating better approaches to this laudable goal.

\section{INTEGRATED STEM PEDAGOGICAL STRATEGY FOR TRAINING THE PRE-SERVICE MATHEMATICS TEACHERS}

Knowledge of pedagogy in teaching iSTEM improves the pre-service mathematics teacher practice to explicitly address the teaching strategy necessary to know the ways to incorporate the pedagogical knowledge in order to have the ability to teach the iSTEM course. Moreover, Knowledge of pedagogy is a set of activities systematically employed by the teachers that involve specific steps to get learners outcome [24]. Also, according to Roberts and Cantu [25] pedagogical strategy is a meaningful way in which the teacher understands and uses a variety of instructions to develop a deep understanding of content areas and build skills in applying the knowledge. Figure 1 illustrates five levels hierarchical iSTEM education teaching trajectory reflecting teacher engagement practised.

The difference between every strategy depends on the degree to which the STEM contents are used in the teaching of the iSTEM education. The integration can take place in a variety of ways based on the various strategy of content across subject areas to promote relevance through real-world problems. The instructional strategy of integrated STEM includes level one: single discipline; level two: combine discipline; level three: multiple disciplines; level four: transdisciplinary (engineering design); and level five: full integration of STEM.

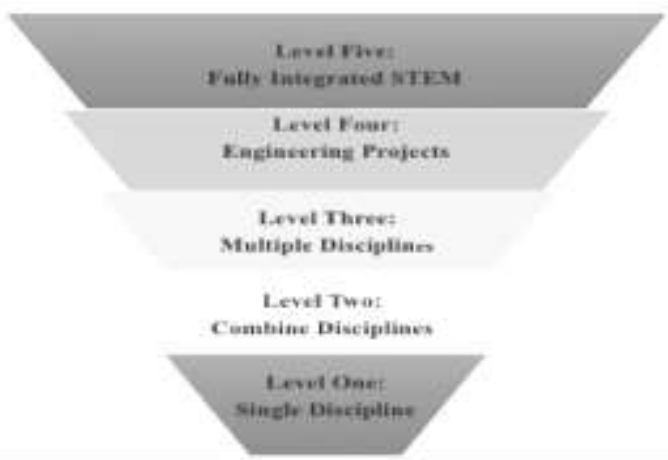

Fig 1. The Five-Levels of iSTEM (adapted from Burrows \& Slater, 2015)

\section{Level One: Single Discipline}

This level of pedagogical strategy indicates the unique and single teaching approach within each individual discipline of the STEM [26]. The content areas are taught separately and there is no explicit STEM integration in this level of instruction. As opined by English [16], in a single discipline, concepts and skills are learned separately in each discipline. Figure 2 depicts the single discipline strategy. In this level, mathematics for the sake of mathematics and no clear on the integration of STEM disciplines as such content areas are separately taught [27]. The challenge discovers at this level is that training is received by most of the STEM teachers is in only one discipline and no formal training on integrating the STEM disciplines cohesively [14]. 


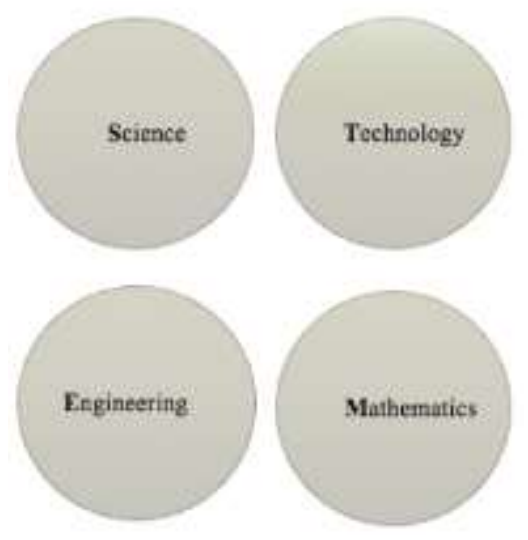

Fig 2. Single STEM discipline

In figure 2 above, each circle symbolised a STEM discipline. The fields are treated separately which keeps each knowledge domain within its boundary. There are prospective shortcomings associated with this type of STEM instruction. First, Breiner, Harkness [28] indicated that it is possible to single discipline pedagogical strategy may not help the learners to understand the integration which occurs between STEM disciplines in the real world. As such, it is possible that this instruction may encourage the learners to maintain a segregated conception of content courses. Secondly, Burnett and Myers [29] suggested that a single discipline strategy may tempt the teachers to rely on a lecture-based methodology rather than a hands-on strategy, which research indicates is more desirable for learning. In single STEM discipline, iSTEM-course training for pre-service mathematics teachers was presented with the nature and goal of iSTEM education and was asked to brainstorm and illustrate about the meaning of STEM as a discipline, iSTEM education and the idea of each component of STEM disciplines.

\section{Level Two: Combine Disciplines}

This level of pedagogical strategy draws attention for connection between two STEM disciplines of mathematics and science; mathematics and technology; or mathematics and engineering. The combined disciplines have been connected to make the discipline related and meaningful to the learners. Mathematics, when connected with science, offers teachers the chance to apply the discipline to real-world issues, the issues that are relevant to the learners' world and bestowed from their point of view. Mathematics for Science, according to Huntley [27] is a mathematics course in which the content and/or method for the sake of science is used to establish the context and relevance of the problem. The pre-service mathematics teachers learn the fact that the classifications of science, as well as the classifications of mathematics, are interrelated and relevant to the teaching and learning of iSTEM course. The connections between mathematics and/or the field of science are pre-eminent. However, there exists the time when the classification of science or mathematics should be separately taught so that the learners will know the basics concepts, procedures and skills necessary to teach iSTEM. Figure 3 represents the combined discipline strategy.

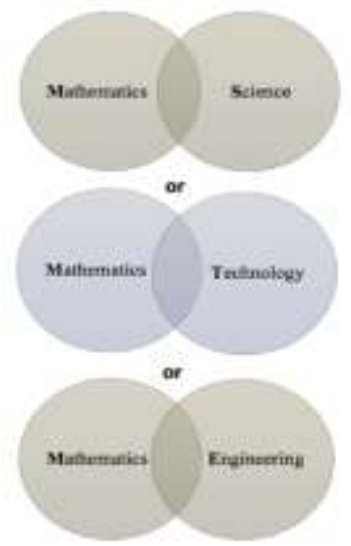

Fig 3. Combine Disciplines for teaching iSTEM course

In figure 3 above, the instruction is taught between and within two STEM disciplines. This level of pedagogical strategy of teaching iSTEM draws attention to the connections between the fields of mathematics and science; Mathematics and technology; and mathematics and engineering. In finding out how to integrate mathematics and science, Berlin and White [30]; Furner and Kumar [9] have recommended that there is need to integrate where there is an overlapping content in mathematics and science. This provides opportunities to put ideas together for better understanding and help students understand that mathematics and science are everywhere. The integration of science and mathematics is essential to develop a deep understanding of both subjects because they complement and improve the understanding of others [31]. In the combine disciplines level, during iSTEM-course training, the researchers assist and guide the participants in working in a small group, make reflection and draw a mind map in illustrating the combine mathematics and science in teaching iSTEM lesson into their classroom instruction.

\section{Level Three: Multiple Disciplines}

This level of pedagogical strategy recognises the integration among more than two STEM disciplines that focused on the connection between discipline and the real-world problems in order for the learners to enhance the understanding of STEM concepts of mathematics, science and technology and/or mathematics, science and engineering $[32,33]$. Figure 4 depicts the multiple discipline strategy of integrated STEM course.

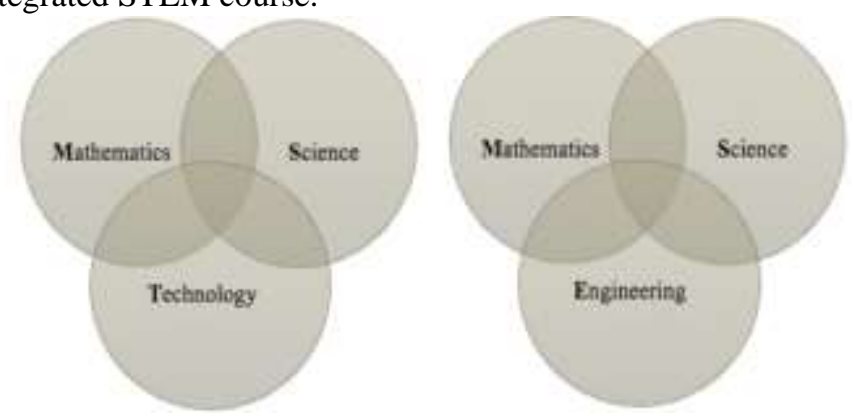

Fig 4. Multiple disciplines for teaching iSTEM course

In this level of integration, 
the instruction is taught among more than two STEM disciplines that recognise the mutual relationships between areas that are more than seeing the integration between them. The integration for multiple disciplines requires numerous materials and resources for the pre-service mathematics teachers to brainstorm and harmonizing the idea of putting multiple STEM disciplines together in solving the real-world problems and for incorporating iSTEM into their classroom instruction.

\section{Level Four: Engineering Projects}

Teachers and curriculum designers working at this level purposefully include engineering and design projects to help advance students and teachers to better understand the real-world problems. Integrated STEM can occur in multiple ways that include engineering design as a basis for creating connections to concepts and from mathematics and/or science $[34,35]$. However, it is discovered in the study of Heba, Mansour [36] that, engineering design is the least mentioned discipline to be integrated with the STEM discipline. However, there is need for iSTEM activities that use engineering design to improve the learners' interest towards iSTEM using five cycles of BITARA-STEM framework [34, 35 ] that includes ask; imagine; plan; create; improve as

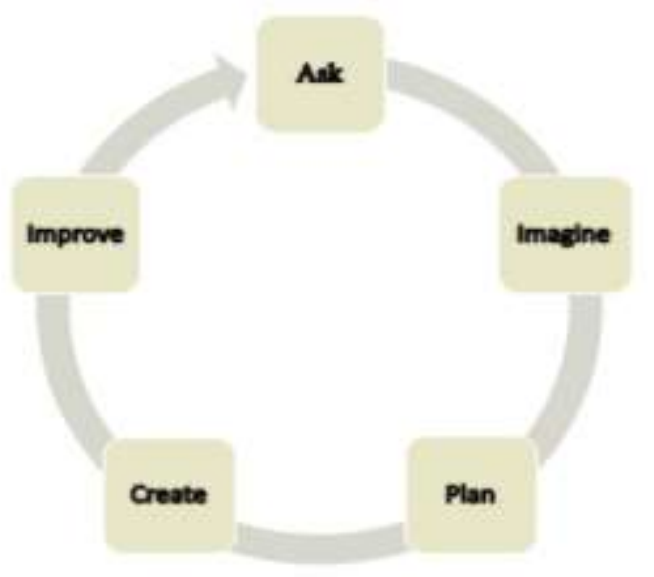

Fig 5. BITARA-STEM framework (adapted from Shahali et al, 2016)

In this level, the learners have to be able to ask to understand the design process and applying mathematics and science to engineering problems; imagining and brainstorm ideas in choosing the best one to engage in the design of engineering process; plan carefully, think and use creativity to understand the materials and their properties in solving engineering problems; create a feasible design solution from a plan; and improve the design solution and learn from failure. More so, the engineering project immensely increases the following impact on the teachers through readiness to teach iSTEM lessons; make teachers be aware of the local iSTEM resources; knowledge of iSTEM workforce; engagement of teachers in iSTEM education; and fun to teach! [36, 37].

In this level, the researchers provide the materials necessary for making engineering projects, guide and support the pre-service mathematics teachers to design and construct simple projects such as the paper plane, paper and spaghetti tower and bridges. This generates the ideas in their reflection depicted in figure 5 .

for teaching the iSTEM lessons and illustrates the application of mathematics, science and engineering from the project constructed.

\section{Level Five: Fully Integrated STEM}

This is the ultimate goal of iSTEM pedagogical strategy which is moving towards the most highly integrated STEM level. The fully integrated STEM strategy is aimed to eliminate the barriers between each of the content areas of the STEM and teach them as one single discipline [28]. Furthermore, integration at this level implies that preservice mathematics teachers receive teaching that emphasizes the applications and interconnectivity that integrate all STEM disciplines [1, 3]. The integrated STEM tries to create a connection between real-world learning using full STEM content rather than a delivery of each content by parts that require a subsequent reformulation of meaningful knowledge [38]. Figure 6 depicts the fully integrated STEM strategy for teaching the iSTEM course.

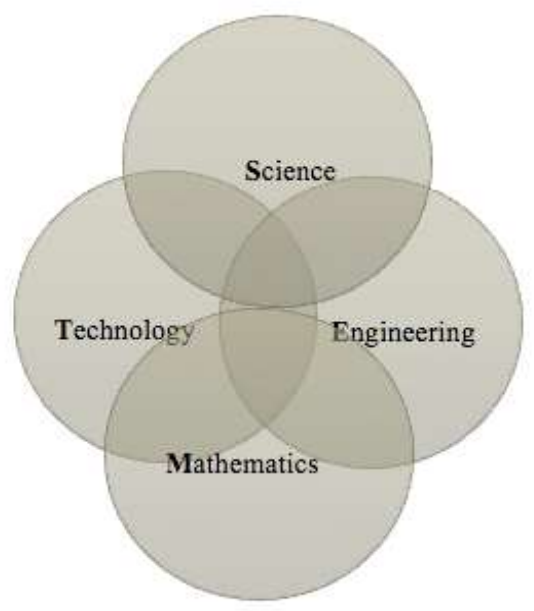

Fig 6. Fully Integrated STEM

In this level of integration, all the STEM disciplines are taught as yet they were one discipline. According to Kelley and Knowles [39], all the potential to prepare integrated STEM stakeholders is to start by combining their conceptual understanding of integrated STEM education through pedagogical training. This can be enhanced when the teacher has a deep understanding of the knowledge of content and the knowledge of the pedagogy [40]. In this study, the pre-service mathematics teachers were constantly involved and participated in hands-on activities, collaboration and team-work in the integrated STEM-course. These are the physical activities that improved the understanding, skills and readiness of the pre-service teachers of mathematics to teach the iSTEM courses.

\section{RESEARCH QUESTIONS}

The purpose of this study was to determine the effectiveness of the iSTEM course as a new pedagogy for training the pre-service mathematics teachers to integrate STEM disciplines. 
This study guided by the following research questions:

RQ1: What is the pre-service mathematics teacher's readiness towards the pedagogical strategy of teaching the iSTEM lessons before and after receiving the iSTEM-course?

RQ2: Is there any significant difference in the readiness of the pre-service mathematics teachers towards the pedagogical strategy for teaching iSTEM lessons?

\section{V.RESEARCH METHODOLOGY}

The one-group pre-test and post-test survey quasi experimental design were used for this research. The integrated STEM pre-test and post-test survey questionnaire (iSTEM-SQ) instruments used for this study both contained same questions and were used to determine the change in the improvement of pre-service mathematics teachers in their readiness to teach the iSTEM lessons. The pre-survey was administered at the beginning of the iSTEM-course training in order to determine the prior knowledge and the iSTEM pedagogical strategy and readiness of the pre-service mathematics teachers before receiving the iSTEM-course training (intervention). At the end of the intervention, the post-test survey was administered to the participants to measure their shifts after receiving the intervention.

\section{A. Participants of the Study}

In this study, the purposeful sampling method was used to select all the 54 pre-service mathematics teachers in their 300 level in the Faculty of Education in Sokoto State University, Nigeria in their second semester 2017/2018 academic session. Pre-service mathematics teachers were chosen due to their capability and willingness to embrace change and they can be trained and equipped today with the iSTEM teaching strategies to handle the rigours of the iSTEM-based curricula tomorrow. This assertion aligns with the study of Koirala and Bowman [12] that indicated pre-service mathematics teachers are much more likely to emphasise and appreciate integrated teaching strategies within and during their teaching method course. The pre-service mathematics teachers have also enrolled in the two different courses, namely, a special method of teaching mathematics course and Science, Technology, and Society course in the university teacher education program. However, besides all these courses the participants were not explicitly aware and familiar with the integrated STEM in which iSTEM education is included as a part of these courses.

\section{B. Integrated STEM Course Training}

The iSTEM-course for training the pre-service mathematics teachers in this research was designed and divided into five levels of integration to cover a period of five weeks. This training was conducted on a weekly basis in which, 3 hours was allotted for every week up to the duration of five weeks. The weekly modules covered five different levels named Single, Combine, multiple, Engineering design and Fully integrated STEM disciplines. The activities in the modules engage the participants to work in a group, engineering design projects involving hands-on activity and teamwork among the participants bridge to connect STEM disciplines together based on the real-world application in the construction of STEM learning activities. These activities build and improve the learner's achievement more in mathematics, science, and engineering concepts into concrete real-life applications that would make the field of mathematics education more relevant and effective in building mathematics understanding. The iSTEM course module was validated by the experts and it was found to be relevant and also serve as a pedagogical scheme for training the iSTEM course.

\section{Data Collection}

Data was collected through the pre-survey and post-survey using the 5-item iSTEM Survey Questionnaire (iSTEM-SQ) having the same content and questions. The iSTEM-SQ was used to determine the change in the improvement of the participants readiness to teach the iSTEM course. The questionnaire items addressed the pedagogical knowledge, content knowledge, curricula knowledge, the conceptions of the iSTEM and instructional strategies for teaching the iSTEM course. The participant's responses were collected using a 5-point Likert scale in which they indicated their level of agreement with the statements about their pedagogical readiness for teaching integrated STEM course. The participants were asked to select from the following: "Strongly Disagree, Disagree, Unsure, Agree, or Strongly Agree." The Pre-test was conducted before receiving the intervention on pedagogical strategies for teaching iSTEM-course. The Post-test survey was also conducted after receiving training on the pedagogical strategies for teaching iSTEM-course. The post-survey was conducted 5 weeks after the pre-survey.

\section{D.Data Analysis}

The data analysis was conducted to analyse the scores of the pre-service mathematics teachers based on the research questions using descriptive statistics that include: median, percentage and frequency counts used on the five categories for the readiness level of pedagogical strategies for teaching the iSTEM lessons. The bar graph and Wilcoxon Signed Ranks for related sample test were used in describing the effectiveness of the pre and post survey responses of the pre-service mathematics teachers' readiness level on the pedagogical strategy for teaching iSTEM lessons. The PQ (PQ1-PQ5) stands for Pre- and Post-survey questions. Also, the following were assigned as a cut off values to the 5-point Likert scale [(Maximum - Minimum) / Group] used in this research, 1 Strongly Disagree (1.00 to 1.80$) ; 2$ Disagree (1.81 to 2.60); 3 Unsure (2.61 to 3.40); 4 Agree (3.41 to 4.20); and 5 Strongly Agree (4.21 to 5.00). In taking the decision, any item with a median value greater than 3.40 was considered as agree; while any item with a median value of less than 3.40 was considered as disagree [41]. Furthermore, in the course of analysing the results, the researcher collapsed the two of Strongly Agree + Agree to give Agree and likewise Strongly Disagree + Disagree to give Disagree. While the Unsure remains stand. 
International Conference on Recents Advancements in Engineering and Technology (ICRAET-18) |15th and 16th March 2019|Siddhartha Institute of Technology \& Sciences, Telangana, India.

\section{RESULTS AND FINDINGS}

The results of this study were obtained by a descriptive analysis of the results of RQ1 as shown in Table 1-5 below. Likewise, an analysis of the results of each item in iSTEM-SQ was tabulated as shown in Table 6 before intervention in pre-test survey (PRETQ1-PRETQ5) and after the intervention in post-test survey (POSTQ1-POSTQ5). Overall, the findings have revealed that iSTEM-course training increases the participants readiness to teach iSTEM lessons in their future classroom instruction.

Research Question One (RQ1): What is the Readiness of the Pre-service Mathematics Teachers Towards the Pedagogical Strategy of Teaching iSTEM Lessons Before and After Receiving the Intervention on iSTEM-Course

The frequency counts and percentages of pre-survey and post-survey are shown in Table 1-5 about the responses collected from the respondents before and after the intervention on the training given to the participants on pedagogical strategies for teaching iSTEM course. Table 1 shows the results for the analysis of the pre-service mathematics teachers responded to the iSTEM-SQ in both before and after the intervention. The responses collected for pre-test question one before the intervention (PRETQ1) indicated that only $4(7.5 \%)$ out of the 54 respondents agreed; $44(81.4 \%)$ disagreed; and $6(11.1 \%)$ were unsure in their readiness to teach the iSTEM course. While after receiving the intervention in the post-test question one (POSTQ1) in which $48(88.9 \%)$ agreed and both $3(5.6 \%)$ each disagreed and unsure about their readiness on the pedagogical strategies to teach the iSTEM course in their future instruction. This signified the improvement in the participants positive results of $81.3 \%$ increase after receiving the intervention.

Table 1 PQ1: Readiness in Teaching Integrated STEM Course.

\begin{tabular}{lrccc}
\hline & \multicolumn{2}{c}{ PRETQ1 } & \multicolumn{2}{c}{ POSTQ1 } \\
& Count & Percent (\%) & Count & Percent (\%) \\
\hline Strongly Disagree & 26 & 48.1 & 1 & 1.9 \\
Disagree & 18 & 33.3 & 2 & 3.7 \\
Unsure & 6 & 11.1 & 3 & 5.6 \\
Agree & 3 & 5.6 & 33 & 61.1 \\
Strongly Agree & 1 & 1.9 & 15 & 27.7 \\
Total & $\mathbf{5 4}$ & $\mathbf{1 0 0}$ & $\mathbf{5 4}$ & $\mathbf{1 0 0}$ \\
\hline
\end{tabular}

Table 2 below illustrates the responses collected before the intervention for the pre-test question two for pedagogical strategy for pre-service (PRETQ2) in which only 3(5.6\%) out of 54 participants agreed with the statement on readiness for having the knowledge to integrate STEM in their classroom instruction; 49(90.7\%) disagreed; and 2(3.7\%) were unsure. A significant positive increase of $81.4 \%$ in the responses was recorded from the respondents after receiving the intervention in the post-test question two (POSTQ2) in which 47(87.0\%) agreed; $3(5.6 \%)$ disagreed; and $4(7.4 \%)$ were unsure about their readiness in teaching the iSTEM in their future classroom instruction.
Table 2 PQ2: Knowledge for Integrating STEM in the Classroom instruction

\begin{tabular}{ccccc}
\hline & \multicolumn{2}{c}{ PRETQ2 } & \multicolumn{2}{c}{ POSTQ2 } \\
& Count & Percent $(\%)$ & Count & Percent (\%) \\
\hline Strongly Disagree & 18 & 33.3 & 2 & 3.7 \\
Disagree & 31 & 57.4 & 1 & 1.9 \\
Unsure & 2 & 3.7 & 4 & 7.4 \\
Agree & 2 & 3.7 & 16 & 29.6 \\
Strongly Agree & 1 & 1.9 & 31 & 57.4 \\
Total & $\mathbf{5 4}$ & $\mathbf{1 0 0}$ & $\mathbf{5 4}$ & $\mathbf{1 0 0}$ \\
\hline
\end{tabular}

Table 3 shows that the responses collected before the intervention on pre-test survey question three (PRETQ3) indicated that only $4(7.5 \%)$ out of the 54 respondents agreed with the statement on the readiness in connecting mathematics concepts to those of engineering, science, and technology. While $46(85.1 \%)$ disagreed and 4(7.4\%) were unsure. An increase in responses of $83.2 \%$ was recorded from the respondents after receiving the intervention on post-test survey question three (POSTQ3) in which 49(90.7\%) agreed $3(5.6 \%)$ disagreed; and $2(3.7 \%)$ were unsure about their readiness to connect mathematics concepts with that of engineering, science, and technology.

Table 3 PQ3: Connecting Mathematics Concepts to Engineering, Science, and Technology

\begin{tabular}{crccc} 
& \multicolumn{2}{c}{ PRETQ3 } & \multicolumn{2}{c}{ POSTQ3 } \\
& Count & Percent $(\%)$ & Count & Percent (\%) \\
\hline Strongly Disagree & 30 & 55.5 & 1 & 1.9 \\
Disagree & 16 & 29.6 & 2 & 3.7 \\
Unsure & 4 & 7.4 & 2 & 3.7 \\
Agree & 1 & 1.9 & 19 & 35.2 \\
Strongly Agree & 3 & 5.6 & 30 & 55.5 \\
Total & $\mathbf{5 4}$ & $\mathbf{1 0 0}$ & $\mathbf{5 4}$ & $\mathbf{1 0 0}$ \\
\hline
\end{tabular}

Table 4 revealed that the responses collected before the intervention on pre-test survey question four (PRETQ4) show that only $3(5.6 \%)$ out of the 54 respondents agreed with the statement on the readiness to guide the learners to use and solve the iSTEM problems by themselves. While $48(88.8 \%)$ disagreed and $3(5.6 \%)$ were unsure. A positive increase of $86.9 \%$ was recorded from the respondents after receiving the intervention on post-test survey question four in which $50(92.5 \%)$ agreed and both $2(3.7 \%)$ each disagreed and unsure about their readiness to guide the learners to use and solve the iSTEM problems by themselves.

Table 4

PQ4: Guiding the Learners to Use and Solve the iSTEM Problems

\begin{tabular}{ccccc} 
& \multicolumn{2}{c}{ PRETQ4 } & \multicolumn{2}{c}{ POSTQ4 } \\
& Count & Percent $(\%)$ & Count & Percent (\%) \\
\hline Strongly Disagree & 20 & 37.0 & 1 & 1.9 \\
Disagree & 28 & 51.8 & 1 & 1.9 \\
Unsure & 3 & 5.6 & 2 & 3.7 \\
Agree & 1 & 1.9 & 29 & 53.7 \\
Strongly Agree & 2 & 3.7 & 21 & 38.8 \\
Total & $\mathbf{5 4}$ & $\mathbf{1 0 0}$ & $\mathbf{5 4}$ & $\mathbf{1 0 0}$ \\
\hline
\end{tabular}

Table 5 shows that the responses collected before the intervention (PRETQ5) indicated that only 5(9.3\%) out of the 54 participants agreed with the statement on the readiness to 
use hands-on activities to teach the iSTEM lessons to their students. While 45(83.3\%) disagreed and 4(7.4\%) were unsure. A significant positive increase in responses of $81.3 \%$ was recorded from the respondents after receiving the intervention on post-test survey question five (POSTQ5) in which 49(90.6\%) agreed; $2(3.8 \%)$ disagreed, and 3(5.6\%) were unsure about their readiness to use hands-on activities to teach the iSTEM lessons to their students.

Table 5 PQ5: Confidence in Using Hands-on Activities to Teach iSTEM Course

\begin{tabular}{ccccc}
\hline & \multicolumn{2}{c}{ PRETQ5 } & \multicolumn{2}{c}{ POSTQ5 } \\
& Count & Percent (\%) & Count & Percent (\%) \\
\hline Strongly Disagree & 26 & 48.1 & 1 & 1.9 \\
Disagree & 19 & 35.2 & 1 & 1.9 \\
Unsure & 4 & 7.4 & 3 & 5.6 \\
Agree & 3 & 5.6 & 15 & 27.7 \\
Strongly Agree & 2 & 3.7 & 34 & 62.9 \\
Total & $\mathbf{5 4}$ & $\mathbf{1 0 0}$ & $\mathbf{5 4}$ & $\mathbf{1 0 0}$ \\
\hline
\end{tabular}

RESEARCH QUESTION TWO (RQ2): Is There any

Significant Difference in the Readiness of the Pre-service
Mathematics Teachers Towards the Pedagogical Strategies for Teaching iSTEM Lessons?

Table 6 shows the results of pre-test survey and post-survey responses in the readiness of the pre-service mathematics teachers towards the pedagogical strategy for teaching the iSTEM course. Unfortunately, it is surprising to observe that the scores of all the responses of the participants before the intervention were below the cutoff point of 3.40 which indicated that, the participants were disagreed for having the readiness in pedagogical strategy to teach the iSTEM course. While an encouraging result was obtained by the participants after receiving the intervention. The results indicated that the scores of all the responses after the intervention were greater than the cutoff point of 3.40 which signified that, the participants were agreed for having the readiness in pedagogical strategy to teach iSTEM lessons in their classroom instruction.

Table 6 Results of PRETQ1- PRETQ5 and POSTQ1- POSTQ5

\begin{tabular}{lrrrrrrrrrr}
\hline & PRET & PRET & PRETQ & PRET & PRETQ & POST & POSTQ & POST & POSTQ & POSTQ5 \\
& Q1 & Q2 & 3 & Q4 & 5 & Q1 & 2 & Q3 & 4 & 54 \\
\hline N Valid & 54 & 54 & 54 & 54 & 54 & 54 & 54 & 54 & 54 \\
\multirow{2}{*}{$\begin{array}{l}\text { Missing } \\
\text { Median }\end{array}$} & 0 & 0 & 0 & 0 & 0 & 0 & 0 & 0 & 0 & 0 \\
\hline
\end{tabular}

Figure 7 shows a chart for the results from Table 6 comparing the scores of the participants according to pedagogical strategies on pre- and post-test survey. This showed a significant increase in the scores of post-surveys for the pedagogical strategy after participating in the iSTEM-course. In the pre-test survey, all the scores indicated that the participants were disagreed for having the readiness in pedagogical strategy to teach iSTEM lessons. Interestingly, the scores of the post-survey all indicated that the participants were agreed for having the readiness in pedagogical strategy to teach the iSTEM lessons in their classroom instruction.

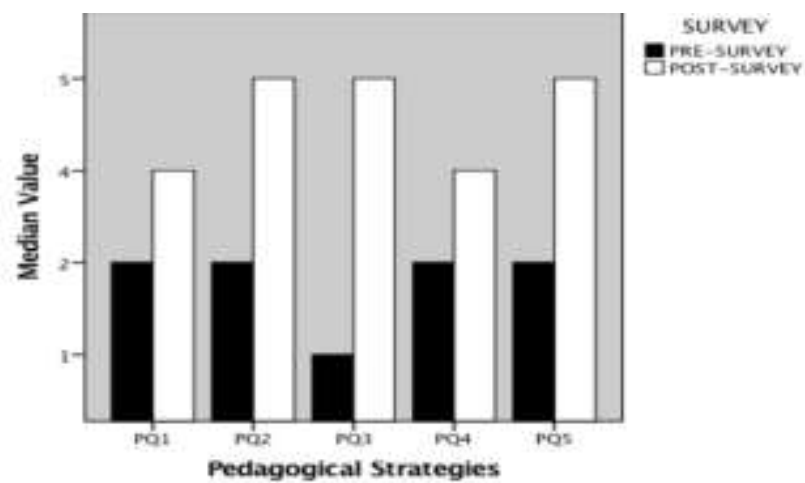

Fig 7. Scores of the pre-test and post-test Survey (PQ1-PQ5)

As seen in Table 7 the results of the Wilcoxon Signed Ranks test analysis showed that there was a significant difference between the scores at a significant level of 0.05. All the items have similar values of $\mathrm{p}=0.000$ which were smaller than the value of $\cdot=0.05(\mathrm{p}=0.000<0.05)$. These significant differences are in favour of the survey after the intervention about the pre-service mathematics teachers' readiness in pedagogical strategy to teach iSTEM lessons in their classroom instruction.

Table 7 Wilcoxon Signed Ranks for Related Sample Test Analysis of Pre- and 
International Conference on Recents Advancements in Engineering and Technology (ICRAET-18) |15th and 16th March 2019|Siddhartha Institute of Technology \& Sciences, Telangana, India.

Post-survey Questions

\begin{tabular}{|c|c|c|c|c|c|c|}
\hline $\mathbf{P Q}$ & POSTQ-PRETQ & $\begin{array}{l}\text { Negative Ranks } \\
\text { (POSTQ<PRETQ) }\end{array}$ & $\begin{array}{l}\text { Positive Ranks } \\
\text { (POSTQ>PRETQ) }\end{array}$ & $\begin{array}{c}\text { Ties } \\
\text { (POST=PRETQ) }\end{array}$ & $\mathrm{Z}$-value & $\begin{array}{c}\text { Asymptotic Significance } \\
\text { (2-tailed) }\end{array}$ \\
\hline PQ1 & POSTQ1-PRETQ1 & 3 & 49 & 2 & -6.139 & 0.000 \\
\hline PQ2 & POSTQ2-PRETQ2 & 2 & 50 & 2 & -6.281 & 0.000 \\
\hline PQ3 & POSTQ3-PRETQ3 & 0 & 48 & 6 & -6.116 & 0.000 \\
\hline PQ4 & POSTQ4-PRETQ4 & 2 & 51 & 1 & -6.317 & 0.000 \\
\hline PQ5 & POSTQ5-PRETQ5 & 1 & 51 & 2 & -6.332 & 0.000 \\
\hline
\end{tabular}

$\mathrm{P}<0.05$ indicates a significant change from pre-test and post-test survey

\section{DISCUSSION OF THE FINDINGS}

The effect of applying the five levels of integration in training the pre-service teachers on the iSTEM pedagogical strategies are heavily acknowledged in the literature. This study has provided the ways in which pre-service mathematics teachers were engaged in the process of teaching the iSTEM-based practice. Generally, the findings of this research have revealed that the participant's pedagogical strategy of teaching the iSTEM increases significantly after receiving iSTEM-course training. The findings show that the training of the participants for the period of 5-week on the five-level of the iSTEM on single, combine, multiple, engineering design projects, and fully integrated STEM and the application of engineering design process in training hands-on activities were consistence. These levels are characterised by the number of the iSTEM aspects, which are combined to teach the iSTEM-based strategy [14].

It is encouraging to report that, further analysis on participants responses categories (Table 6, Table 7 and Figure 7) indicated that, our iSTEM-course intervention was effective in training our participants pedagogical strategy of teaching the iSTEM-course. The overall outcomes of this study indeed provide evidence that the iSTEM-course training has a positive effect on the participants as a new pedagogy for preparing and empowering them for teaching the iSTEM in their future classroom instruction.

\section{LIMITATIONS OF THE STUDY}

The limitations of this study provide excellent contexts and indications for future research in this line of research in the iSTEM course using pre-service mathematics teachers. This study is limited to only one group and a small number of participants. Since the research design did not include a control or comparison group, it is not possible to attribute the findings of this study to the iSTEM training course alone, nor the results can be generalized. The interpretation of the results must consider the fact that the control group does not exist and we are reporting the perception of the respondents. The limitation of reported data was considered, but this is consistent with the study of [42] whose made a judgement that, reported data was the most useful measurement tool for practical assessment.

\section{CONCLUSION}

The iSTEM-course was designed to train the pre-service mathematics teachers involved in this study with the iSTEM-based pedagogy and to be transformed from receiving

training in separate STEM disciplines to integrated STEM-based practices into their classroom instruction. Thus, it can be concluded that the intervention received by the participants significantly influence and change their abilities positively about the pedagogical strategy of teaching the iSTEM course. The training utilized several promising practices such as the readiness of the participants in teaching and learning the iSTEM, their participation in hands-on learning activities, learning experience through small group work, brainstorming, creativity, reflections, and engagement in collaborative ideas in conducting the iSTEM activities by themselves also was a plus to the effectiveness of the iSTEM-course training. The analysis of the participants responses in pre-survey and post-survey showed the improvement of their learning. Table 6 shows the scores of post-surveys of all the participants were higher than that of the pre-survey. This is consistent with the study conducted by Dooley, Atkinson-Hamilton [42] who had used conference participants results which indicated there was a significant change in pretest and posttest in making an overall positive impact on pre-service teachers familiarity and belief in the importance of STEM-education.

\section{A. Suggestions for Further Study}

This study suggests that a future study could be designed to involve two groups with a large number of pre-service mathematics teachers on the effect of an iSTEM-course. Further research should explore and improve on the design that would produce large positive increases on the variables being studied.

\section{ACKNOWLEDGMENT}

We are thankful to Universiti Teknologi Malaysia (UTM) and the Malaysian Ministry of Higher Education for supporting this research under Grant No. 4F942. Any viewpoints, findings, conclusions or suggestions expressed are the authors and do not necessarily reflect the view of the UTM or the Malaysian Ministry of Higher Education.

\section{REFERENCES}

1. Shernoff, D.J., et al., Assessing teacher education and professional development needs for the implementation of integrated approaches to STEM education. International Journal of STEM Education, 2017. 4(1): p. 13.

\section{Nadelson, L.S. and A.L.}


Seifert, Integrated STEM defined: Contexts, challenges, and the future. The Journal of Educational Research, 2017. 110(3): p. 221-223.

3. Stohlmann, M., T. Moore, and G. Roehrig, Considerations for Teaching Integrated STEM Education. Journal of Pre-College Engineering Education Research, 2012. 2(1): p. 28-34.

4. Fogarty, R., Ten ways to integrate curriculum. Educationa leadership, 1991. 49(2): p. 61-65

5. Okpala, P.N., Reforms in Science, Technology, Engineering and Mathematics (STEM) Education, in Keynote Address 54th Science Teachers Association of Nigeria (STAN). 2012

6. Ugo, E.A., Akpoghol T.V., Improving Science, Technology, Engineering and Mathematics (STEM) Programs in Secondary Schools in Benue State Nigeria: Challenges and Prospects. Asia Pacific Journal of Education, Arts and Sciences, 2016. 3(3): p. 6-16

7. Yusha'u, M., Effective Use of Teaching Methodologies in Science, Technology and Mathematics (STM) Classrooms in Nigeria: A Panacea to Vision 20: 2020. International Journal of Education and Practice, 2015. 3(3): p. 114-121.

8. Muhammad, R., An Assessment of Science, Technology and Mathematics (STM) Teachers' Involvement in Professional Development Activities in Sokoto State, Nigeria. Internationa Journal of Science and Engineering Investigations, 2017. 6(71): p. 157-159.

9. Furner, J.M. and D.D. Kumar, The mathematics and science integration argument: A stand for teacher education. Eurasia journal of mathematics, science \& technology education, 2007. 3(3): p. 185-189.

10. Frykholm, J. and G. Glasson, Connecting science and mathematics instruction: Pedagogical context knowledge for teachers. School Science and Mathematics, 2005. 105(3): p. 127-141.

11. Berlin, D.F. and A.L. White, A longitudinal look at attitudes and perceptions related to the integration of mathematics, science, and technology education. School Science and Mathematics, 2012. 112(1): p. 20-30

12. Koirala, H.P. and J.K. Bowman, Preparing middle level preservice teachers to integrate mathematics and science Problems and possibilities. School Science and Mathematics, 2003. 103(3): p. 145-154

13. Niess, M.L., Preparing teachers to teach science and mathematics with technology: Developing a technology pedagogical content knowledge. Teaching and teacher education, 2005. 21(5): $\mathrm{p}$. 509-523.

14. Burrows, A. and T. Slater, A proposed integrated STEM framework for contemporary teacher preparation. Teacher Education and Practice, 2015. 28(2/3): p. 318-330.

15. National Research Council, Successful K-12 STEM education: Identifying effective approaches in science, technology, engineering, and mathematics. 2011: National Academies Press.

16. English, L.D., STEM education K-12: perspectives on integration. International Journal of STEM education, 2016. 3(1): p. 1-8.

17. Estapa, A.T. and K.M. Tank, Supporting integrated STEM in the elementary classroom: a professional development approach centered on an engineering design challenge. International Journal of STEM education, 2017. 4(1): p. 1-16

18. Zollman, A., Learning for STEM literacy: STEM literacy for learning. School Science and Mathematics, 2012. 112(1): p. 12-19.

19. Bybee, R.W., The case for STEM education: Challenges and opportunities. 2013: National Science Teachers Association.

20. Ukeje, B. The challenges of Mathematics in Nigeria's Economic Goals of Vision 2010: Implication for Secondary School Mathematics. in 34th Annual National Conference of the Mathematical Association of Nigeria (MAN). 1997.

21. Ojimba, D.P., Strategies for Teaching and Sustaining Mathematics as an Indispensable Tool for Technological Development in Nigeria. Medaterranean Journal of Social Sciences, 2012. 3(15): p. 74-79.

22. Bajah, S.T. Emerging global issues in Education. in A lead paper presented at the National Conference on Curriculum innovation in the 21st century. 2000. Abuja, Nigeria.

23. Salau, O. Strategies for sustaining mathematics as an indispensable tool for sustaining technological development in the 21 st century. in 43rd Annual conference proceedings of STAN. 2002
24. Shulman, L., Knowledge and teaching: Foundations of the new reform. Harvard educational review, 1987. 57(1): p. 1-23.

25. Roberts, A. and D. Cantu. Applying STEM instructional strategies to design and technology curriculum. in PATT 26 Conference; Technology Education in the 21st Century; Stockholm; Sweden; 26-30 June; 2012. 2012. Linköping University Electronic Press.

26. Dugger, W.E. Evolution of STEM in the United States. in 6th Biennial International Conference on Technology Education Research in Australia retrieved from http://www. iteea org/Resources/PressRoom/AustraliaPaper. pdf. 2010. Citeseer.

27. Huntley, M.A., Design and implementation of a framework for defining integrated mathematics and science education. School Science and Mathematics, 1998. 98(6): p. 320-327

28. Breiner, J.M., et al., What is STEM? A discussion about conceptions of STEM in education and partnerships. Schoo Science and Mathematics, 2012. 112(1): p. 3-11.

29. Burnett, M.M. and B.A. Myers. Future of end-user software engineering: beyond the silos. in Proceedings of the on Future of Software Engineering. 2014. ACM.

30. Berlin, D.F. and A.L. White, Report from the NSF/SSMA Wingspread conference: A network for integrated science and mathematics teaching and learning. School Science and Mathematics, 1992. 92(6): p. 340-342.

31. Basista, B. and S. Mathews, Integrated science and mathematics professional development programs. School science and mathematics, 2002. 102(7): p. 359-370.

32. Gallant, D.J., Science, technology, engineering, and mathematics (STEM) education. ed: McGraw-Hill Education. Retrieved from https://www. mheonline. com/glencoemath/pdf/stem_education. pdf, 2010.

33. Moore, T., et al., Implementation and integration of engineering in K-12 STEM education. Engineering in precollege settings: Research into practice, 2014: p. 35-60.

34. Shahali, E.H.M., et al., STEM Learning through Engineering Design: Impact on Middle Secondary Students' Interest towards STEM. EURASIA Journal of Mathematics, Science and Technology Education, 2016. 13(5): p. 1189-1211.

35. Thibaut, L., et al., Integrated STEM Education: A Systematic Review of Instructional Practices in Secondary Education. European Journal of STEM Education, 2018. 3(1): p. 1-12.

36. Heba, E.-D., et al., Context of STEM Integration in Schools: Views from In-service Science Teachers. Eurasia Journal of Mathematics, Science and Technology Education, 2017. 13(6) p. 2459-2484.

37. Burrows, A., et al., Integrated STEM: Focus on Informa Education and Community Collaboration through Engineering. Education Sciences, 2018. 8(1): p. 1-15.

38. Tsupros, N., R. Kohler, and J. Hallinen, STEM education: A project to identify the missing components. Intermediate Unit, 2009. 1: p. 11-17.

39. Kelley, T.R. and J.G. Knowles, A conceptual framework for integrated STEM education. International Journal of STEM Education, 2016. 3(1): p. 1-11

40. Nadelson, L.S., et al., i-STEM summer institute: An integrated approach to teacher professional development in STEM. Journal of STEM Education: Innovations and Research, 2012. 13(2): p 69

41. Şehriban, K., An investigation of music teaching self-efficacy levels of prospective preschool teachers. Educational Research and Reviews, 2013. 8(12): p. 897-900.

42. Dooley, A., et al., Analysis of a STEM Education Professional Development Conference for Pre-service Educators. 2017, University of Missouri-Saint Louis. 


\section{AUTHORS PROFILE}

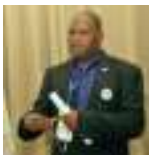

Usman Galadima is a lecturer in the Department of Science Education at the Sokoto State University, Nigeria. He obtained his Master and Bachelor Degrees in Mathematics Education from Usmanu Danfodiyo University, Sokoto, Nigeria. He is currently a PhD student in the School of Education, Universiti Teknologi Malaysia (UTM). He has research interest in pedagogical content knowledge in teaching integrated STEM course, Mathematics Teacher Training and STEM literacy research.

Zaleha Ismail is currently a professor at the Department of Educational Science, Mathematics and Multimedia Creative at Universiti Teknologi Malaysia. Her research interests and publications include teaching and learning of mathematics, mathematical thinking, statistical reasoning, mathematics teacher education, technology integration in mathematics education, STEM and engineering education. She has worked as a researcher, primary and secondary teacher educator, supervisor of graduate research and as a consultant to the Malaysian Ministry of Education for the STEM education and HOTS (high order thinking skills) projects.

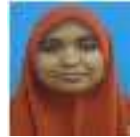

Norulhuda Ismail is a senior lecturer in the Department of Science, Mathematics and Creative Multimedia, School of Education, Universiti Teknologi Malaysia. She obtained her $\mathrm{PhD}$ from the UCL Institute of Education in 2015. Her current research interests include integrated STEM education, student teacher development and approaches to teaching mathematics. 